\title{
Una mirada a la crisis del relato mítico de la Transición: la "Querella argentina" contra los crímenes del franquismo
}

Regarding the Fall of Mythical Narratives On Spanish Transition: the

"Argentinian Complaint" against francoist crimes

\author{
Marina Montoto Ugarte \\ UNIVERSIDAD COMPLUTENSE·mmontotougarte@ucm.es
}

Licenciada en Sociología (UCM) en 2012, y Máster de Antropología Social y Cultural (UCM) en 2013, con un trabajo final sobre la construcción hegemónica del discurso de la Transición española. Actualmente se encuentra realizando la tesis doctoral "La lucha por la historia legítima: pugnas y procesos de subjetivación en la querella argentina contra los crímenes del franquismo". Investiga también sobre discursos y culturas militantes en el Estado Español, y es integrante del colectivo Memorias en red.

RECIBIDO: 1 DE NOVIEMBRE DE 2014 ACEPTADO: 13 DE DICIEMBRE DE 2014

Resumen: Este artículo es una primera aproximación al análisis de un espacio social, tradicionalmente no definido como producto cultural, pero que, como cualquier otro, revisita y reformula desde la perspectiva actual de crisis el relato mítico de la Transición. La querella argentina contra los crímenes del franquismo, y el espacio social que genera, es un producto cultural diferente, por sus propias dinámicas y su propio campo de juego, y hace que sea necesario seguir su proceso con una mirada atenta y diferente, prometiendo enriquecer un debate ya abierto en la literatura académica, como es el actual proceso de reelaboración colectiva sobre la historia del siglo $\mathrm{XX}$ en España.

Palabras Clave: Transición española, Derechos Humanos, discursos sociales, Régimen del 78, sujetos sociales, Querella Argentina.
Abstract: This article is a first approach to the analysis of a social space that traditionally have not been defined as a cultural product, but, as anyone else, revisits and reformulates from the current perspective of the crisis the mythical story of the Transition, The Argentina complaint against the crimes of Francoism, and the social space that it generates, is a different cultural product by its own dynamics and its own field that makes necessary to analyze the process carefully and with a different look, promising enrich the already opened debate in the academic literature, as it is the current process of collective reelaboration of the history of the twentieth century in Spain.

Key Words: Spanish Transition, Human Rights, Social Discourses, 78th Regime, Social Subjects, Argentinian Complaint. 
El sociólogo puede tentarse de entrar en el juego, de tener la
última palabra en las querellas de palabras diciendo lo que
realmente ocurre con las cosas. Si, como pienso, lo que le
incumbe como propio es describir la lógica de las luchas a
propósito de las palabras, se comprende que tenga problemas
con las palabras que debe emplear para hablar de esas luchas.

PIERRE BOURDIEU, 1987

\section{Introducción}

En este artículo la autora trata de dar cuenta de un proceso social complejo, como es la actual quiebra o crisis del relato hegemónico de la Transición española, a través de un caso concreto, como es la causa penal internacional de la "Querella Argentina contra los crímenes del Franquismo". En la primera parte del texto se realiza una reconstrucción socio-histórica del contexto de producción y consolidación del relato mítico de la Transición en los primeros años de la democracia, para más adelante dar cuenta de las posibles causas que en la actualidad han llevado a su quiebre o desborde, resumidas principalmente en dos fenómenos fundamentales, como son la irrupción de los movimientos por "la memoria histórica", por un lado, y la crisis del Régimen del 78, por otro. En la segunda parte, se da una primera aproximación al análisis del caso de la "Querella Argentina" como un lugar destacado para dar cuenta de este proceso de reelaboración histórica colectiva, un lugar que, por sus propias dinámicas y su propio campo de juego, los cuales describimos, podría llegar a desempeñar una labor de aceleración del quiebre del relato hegemónico y de potencial lugar de enunciación de nuevas narrativas sobre la historia reciente de nuestro país.

\section{El relato mítico de la Transición.}

Todas las sociedades construyen y ponen en relación relatos y narrativas sobre los procesos políticos y sociales más importantes de su historia colectiva (Halbwachs, 2004). Es una necesidad social ordenar todo ese caos infinito de hechos, fechas o procesos, en un relato que haga una selección de ellos, los enmarque y los dote de sentido. Si bien es cierto que siempre se encuentra una pluralidad de relatos sobre un mismo período, en muchas ocasiones uno de ellos se consolidará, conformándose como el relato hegemónico, como el relato de verdad, primando sobre los otros, convirtiéndose en el marco de memoria histórica dominante (Aguilar, 2007; Halbwachs, 2004).

En el caso español, dentro de los procesos políticos y sociales más importantes de nuestro país se encuentra la Transición española. En los discursos a posteriori sobre el proceso transicional se produjo la consolidación y reproducción de un relato que, aún alejado de la realidad historiográfica (Gallego, 2008), por las circunstancias de inestabilidad política, incertidumbre y conflicto que se vivió en esos años, se consolidó como un mito. Este relato mítico de la Transición contiene a su vez dos narrativas fundamentales. En primer lugar, ha incorporado un relato sobre el proceso transicional: éste da cuenta de la manera en que se dio el proceso de cambio político en los años setenta. Afecta sólo a los 
hechos acontecidos de lo que se ha llamado Transición: dentro de la literatura historiográfica mayoritaria, desde el atentado a Luis Carrero Blanco en 1973 hasta la victoria del Partido Socialista Obrero Español en 1982.

En este sentido, cabe destacar que el contexto de conflicto, miedo y coacción simbólica que se vivió durante la Transición, con una extendida sensación de amenaza de una posible involución política (Oñate, 1998) hizo que, como he planteado en otra parte:

desde las élites políticas se mantuviese una ficción en torno al uso del consenso, del diálogo y de la libertad durante esos años. Esta necesidad impuso una lectura del proceso transicional fuertemente positiva, que se fue consolidando, sin embargo, a lo largo de los años, sin criticarse o reflexionarse a posteriori. Es por eso que, dentro del discurso asumido de la Transición española (...) encontramos un relato de la misma que define el proceso como "modélico" y "pacífico", en torno a cuatro significantes o anclajes importantes: la idea de consenso, la figura de la monarquía, el papel de la Constitución, y la figura de las élites políticas o de la propia sociedad civil española (Montoto y Vázquez, 2013).

Este discurso funcionó durante todo el período transicional, pero de una manera mucho más enérgica después del golpe de Estado del 23 de Febrero de 1981. Así pues, el mito de la Transición se pudo instaurar en el sentido común de las y los españoles, por el que "España logró, contra pronóstico y por una suerte de batallitas, hazañas, y heroicidades, pasar de la dictadura a la democracia por consenso y sin violencia" (Escolar, 2013: 5). Nos encontramos, entonces, con un proceso transicional en la que la necesidad acaba convirtiéndose en virtud, en el que ese medio (un uso ideológico del consenso y el diálogo que tiene como objetivo, en un primer momento, poder superar ese miedo, esa amenaza de un golpe involucionista) acabó convirtiéndose en fin en sí mismo. He aquí el origen del relato mítico de nuestra democracia: el miedo.

En segundo lugar, este relato mítico de la Transición también incorpora, y esto es fundamental, la lectura implícita o explícita sobre hechos anteriores fundamentales de la historia colectiva de España -es decir, la Segunda República, la Guerra Civil y la Dictaduraque se impuso en esos años, los del cambio político. Aquí, encontramos la imposición (o consenso, dependiendo de los espacios sociales) de una interpretación histórica que tilda la Guerra Civil de drama humano y fraticida, en el que "todos fuimos culpables", en donde se mira con equidistancia a los dos bandos. En estas circunstancias trágicas, la única manera de superar ese tremendo trauma es no mirar hacia el pasado, olvidar y perdonar, en un ambiente de "reconciliación" definitiva, por el cual la memoria de la guerra sólo es utilizable para decir "Nunca Más" (Juliá, 2003). En este contexto, la Guerra Civil se asocia de una manera mucho más fuerte con la Segunda República que con la Dictadura; república definida como un periodo oscuro de inestabilidad, conflicto y polarización, definido por algunos autores como la época de "la política absoluta" (Pérez Díaz, 1993).

Es conveniente, en este punto, matizar que todo este proceso no fue solamente -ni mucho menos- un proceso impuesto en su sentido más coercitivo, como podría interpretarse en una lectura simple del poder de arriba abajo, por el que unas élites políticas imponen determinadas lecturas sobre ciertos hechos a una población que simplemente recibe ese discurso. Todo este fenómeno social pudo llevarse a cabo justamente por una 
complicidad con la ciudadanía, la cual también había producido una propia demanda social de olvido y de reconciliación, posiblemente influenciada por un trauma todavía muy profundo de la Guerra Civil y la Dictadura, por un deseo real y legítimo de acercarse por fin a Europa y por el creciente individualismo y apoliticismo que comenzaba a desarrollarse en la nueva sociedad de consumo española que se estaba dando en aquél momento.

En parte gracias al trabajo de asunción y reproducción del mismo por parte de las élites académicas, políticas, periodísticas y culturales (Montoto, 2012) este discurso dominante de la Transición fue consolidándose a lo largo de los años ochenta, para confirmarse en la década posterior como el marco de sentido común del que la mayoría de la ciudadanía haría uso para interpretar los hechos recientes de su pasado colectivo. Sin embargo, en los últimos años muchos elementos marcan la pista de cierta ruptura que, si bien todavía no está claro si podrá sustituir a ese relato mítico de la Transición, es posible ya afirmar con seguridad que lo ha desbordado (Sánchez León, 2012).

\section{Los movimientos por la recuperación de "la memoria histórica"}

Dar cuenta de las causas de este quiebre profundo en el relato mítico y fundacional de la joven democracia española es un trabajo difícil, ya que éstas son múltiples y complejas, a lo que se suma la complicación de tratarse de una realidad viva y cambiante cada día, de manera que los científicos sociales estamos siendo testigos de un proceso que no ha hecho más que comenzar, y en donde, queramos o no, nosotros también intervenimos desde el ámbito académico. Por ello, lo que viene a continuación sólo consiste en un intento parcial de contextualizar y explicar esta crisis y los replanteamientos del relato dominante.

En primer lugar, hay que remontarse a la llegada del nuevo siglo, $\mathrm{y}$ a las primeras asociaciones memorísticas y pro-derechos humanos que, casi sesenta años después, denunciaron el absoluto desamparo de las víctimas y los familiares de la Guerra Civil y la dictadura franquista (en este primer momento, sobre todo en su primera etapa, la más dura y represiva). Se trata de la llegada de lo que luego se ha denominado en España como el movimiento por la "memoria histórica", irrupción promovida, en su mayoría, por los nietos y las nietas de esas víctimas. Fue justamente un nieto de un republicano quien el 8 de octubre de 2000, en la localidad leonesa de Priaranza del Bierzo, desenterró, con el apoyo de la que sería poco después la Asociación Por la Recuperación de la Memoria Histórica, los restos de su abuelo y de doce represaliados más, siendo el primero en identificar a un familiar represaliado mediante la prueba de ADN. El impacto mediático, la constitución de la asociación en diferentes regiones, y la localización de muchas más fosas y demandas de exhumación (muchas aún no satisfechas a día de hoy) de decenas de miles de desaparecidos -palabra eficaz, importada desde los procesos de justicia transicional del Cono Sur y de los nuevos marcos globales de Justicia Universal-, supuso un verdadero boom de memoria histórica primero en el campo mediático, luego en el campo social, y más tarde en el campo político y jurídico.

Este boom tuvo un acompañante y altavoz predilecto en toda esta primera década de los 2000, como fue la cultura. Y es que tanto el mercado cultural como el ámbito académico se llenaron de productos ligados a la recuperación de la memoria de la guerra civil y la dictadura, productos de muy diverso tipo, tanto de unas corrientes ideológicas como de 
otras, y pensadas para un público profundamente diverso. En el ámbito de las industrias culturales, encontramos novelas (Cercas, 2001; Chacón, 2002; Moa, 2003; Grandes, 2007; Rosa, 2007), documentales (Armengou, 2004; García-Alix, 2007), o películas (Cuerda, 1999: Uribe, 2002; Del Toro, 2006), pero también programas de televisión como Cine de Barrio. En la academia, damos paso a una verdadera explosión de investigaciones y publicaciones, tanto desde la historiografía (Aróstegui, 1996, 2004; Juliá, 2004; Casanova, 2008; Izquierdo y Sánchez León, 2006), como desde otras muchas ciencias sociales (Aguilar, 2008; Ferrándiz, 2010, 2014) o científicas (Etxeberría, 2009). Este fenómeno de explosión de un verdadero mercado de la memoria es además fortalecido por un fenómeno parecido y paralelo que a finales del siglo XX ya se ha instaurado en Europa, de auge y consolidación de las temáticas de la historia y memoria europea en los mismos ámbitos ya mencionados, con respecto a hechos históricos fundamentales para ella como la segunda guerra mundial o la caída del bloque soviético, contexto de mirada al pasado y re-visitación que ha llegado a ser criticado por ciertos sectores culturales y académicos (Nora, 1984; Todorov, 2000).

Este proceso de impulso social y cultural de la memoria histórica tuvo sus propias traducciones institucionales, la más importante en el año 2007, con la aprobación en el Congreso de los Diputados, en esos momentos de mayoría socialista, del proyecto de ley 52/2007, "por la que se reconocen y amplían derechos y se establecen medidas en favor de quienes padecieron persecución o violencia durante la guerra civil y la dictadura" (B.O.E. 27/12/2007), más comúnmente conocida como la "Ley de Memoria Histórica". Esta ley daba por fin una cobertura legal a las demandas de las asociaciones de víctimas, reconociendo por primera vez de manera oficial el estatuto de víctima también a todas aquellas personas que habían sufrido la represión del bando franquista en la Guerra Civil y la Dictadura; planteaba además reformas importantes en relación a lugares de memoria controvertidos como "El valle de los caídos" y denunciaba la existencia de placas, estatuas y monumentos franquistas no acordes con un estado democrático y necesarios de ser eliminados.

Sin embargo, el texto tenía importantes limitaciones. En primer lugar, acaba subrayando el carácter familiar y privado de las víctimas, esquivando el marco de "Crímenes de Lesa Humanidad" de las Naciones Unidas, que son crímenes cometidos contra toda la sociedad, negando así el deber del Estado español como garante del cumplimiento de las políticas de Justicia Transicional y Derechos Humanos aprobadas en la comunidad internacional unas décadas antes, muchas de ellas ratificadas por España. Por otro lado, la ley se fundamenta enormemente todavía en el espíritu de reconciliación de la Transición, y por ende en su relato hegemónico, como reza su prólogo:

El espíritu de reconciliación y concordia, y de respeto al pluralismo y a la defensa pacífica de todas las ideas, que guió la Transición, nos permitió dotarnos de una Constitución, la de 1978, que tradujo jurídicamente esa voluntad de reencuentro de los españoles, articulando un Estado social y democrático de derecho con clara vocación integradora (B.O.E. 27/12/2007). 
Pero lo que más interesa destacar aquí es cómo todo este boom de la memoria acabó dándose de bruces, inevitablemente, con el proceso de la Transición española, posiblemente por dos razones fundamentales. Por un lado, debido a una saturación del mercado académico y cultural de todos estos productos sobre la Guerra Civil y la primera dictadura, ya palpable a finales de la primera década del siglo XXI, hasta el punto que el escritor y columnista Isaac Rosa tituló a uno de sus libros ;Otra maldita novela sobre la Guerra Civil. (2007). El campo de la memoria de aquella época ya había dado sus frutos, y comenzaba a plantearse la necesidad de mirar más allá de aquellos lejanos años en busca de nuevas direcciones, como por ejemplo hacia las últimas décadas de la dictadura y de la Transición. Hay que añadir, además, que el propio contexto franquista, represor y dictatorial hasta el final de su régimen -los años setenta del siglo pasado-, permitía una continuidad en estas narrativas, biografías o trayectorias de memoria, tanto en sus productos culturales más mainstream como en las investigaciones académicas, más rigurosas, haciendo lógica una ampliación de todas estas temáticas hasta el final de la dictadura y los principios de la democracia.

Por otro lado, los movimientos de memoria y pro-derechos humanos se toparon con la Transición ya no sólo como campo fértil de historias rescatables, sino como barrera política, jurídica y social. Y es que, muchas de las demandas de las víctimas de la Guerra Civil y la dictadura, elaboradas desde los marcos globales emergentes de Justicia Transicional y Derechos Humanos (Pérez Bonet y Alija Fernández 2009; Teitel, 2003), no podían ser satisfechas justamente por la lectura, tanto social como legal, que la Transición otorgó al golpe militar, al conflicto armado y al posterior régimen de Franco. En este sentido, son cuatro los mecanismos fundamentales de Justicia Transicional que recomiendan las Naciones Unidas de cara al éxito de un proceso de cambio político, normalmente de una situación de ausencia democrática a otra de Estado de derecho. El primero es el derecho a investigar y restablecer oficialmente los hechos del pasado (verdad); el segundo sería el derecho a condenar a los culpables de aquellos delitos no prescritos o de Lesa Humanidad (justicia); el tercero corresponde al derecho a garantizar el debido reconocimiento a las víctimas de las graves violaciones a los Derechos Humanos (reparación); y el último se refiere al establecimiento de garantías duraderas de no repetición. Respecto al primero, el derecho a la verdad, en España la Transición impuso, como hemos apuntado, una política de olvido absoluto (Gil y Gil, 2009 en Chinchón, 2012). De este modo:
no se estableció nunca una política de Estado en materia de verdad, no existe información oficial, ni mecanismos de esclarecimiento de la verdad. El modelo vigente de "privatización" de las exhumaciones, que delega esta responsabilidad a las víctimas y asociaciones, alimenta la indiferencia de las instituciones estatales y conlleva dificultades metodológicas, de homologación y oficialización de la verdad (De Greiff, 2014: 2).

El segundo mecanismo, el derecho a la justicia, se topa con la Ley de Amnistía, uno de los hitos de la Transición, de 1977, y una judicatura española poco proclive a investigar y condenar el franquismo, por su propio ADN franquista (Aguilar, 2013). En relación con el tercero, el derecho a la reparación, ya hemos apuntado anteriormente al modelo de 
reparaciones "privatizadas", a la que sumamos la dificultad por parte de las víctimas de obtener un reconocimiento oficial por parte del Estado (cosa que otras víctimas, por ejemplo las de terrorismo, sí consiguen). Finalmente, sobre las garantías de no repetición, parece que la depuración y la profesionalización de las fuerzas armadas, y el profundo deseo de los españoles de vivir en democracia, ha hecho del Estado español un país estable y con garantías democráticas. De todo ello, podemos concluir que la Transición comenzaba a ser un hecho crucial para la memoria histórica (Bernecker y Sören, 2009) y los movimientos de memoria comenzaban a ponerla sobre la mesa, tanto como barrera que superar, como fuente infinita de nuevos relatos.

\section{La crisis del Régimen del 78}

La otra causa fundamental del quiebre del relato dominante de la Transición ha sido la crisis de su propio régimen político al que -en cierto sentido- este discurso sustentaba: el llamado "Régimen del 78", es decir el régimen político resultante del proceso de Transición y el que ha definido nuestro modelo de democracia estos primeros cuarenta años de post-dictadura. Este régimen se fragua, como todos, como la cristalización de unas contradicciones históricas, económicas y sociales no del todo resueltas en el periodo transicional. En primer lugar se encuentra un modelo territorial del famoso "café para todos", donde el llamado Estado de las autonomías "fomentó el sentido político particularista en áreas donde no existía previamente y nunca llegó a satisfacer a una parte de los ciudadanos de las nacionalidades históricas que sí tenían un sentido identitario propio" (Franco, 2013: 74 en Montoto y Vázquez, 2013). En segundo lugar se encuentra un modelo político con un monarquía marcadamente personalista -hasta tal punto que muchas personas se declararon juancarlistas más que monárquicas- y un bipartidismo cocinado, con un sistema electoral que se ha calificado de proporcional y que, sin embargo, se basa en una fórmula escasamente representativa (Lago y Montero, 2005, citado en Montoto y Vázquez, 2012). Respecto al modelo social, se terminó de desarrollar un régimen de bienestar de tipo mediterráneo, corporativista y familiarista, basado en el pacto social entre los diferentes actores de la sociedad y de la economía (Naldini, 2006) y en la desmovilización de la ciudadanía.

La crisis económica global que explotó en 2008, y -sobre todo- la gestión de la misma por los dos partidos mayoritarios, han hecho estallar estos consensos o engranajes del régimen del 78 en mil pedazos (Montoto y Vázquez, 2013). Por un lado, el modelo territorial se ha visto incapaz de poder incorporar las demandas crecientes de mayor autodeterminación de los nacionalismos periféricos (sobre todo en Catalunya). Por otro lado, la gestión de la crisis por parte de las élites políticas recetando más austeridad y recortes para la ciudadanía ha abierto una profunda grieta entre un clase política -acomodada y salpicada de escándalos de corrupción- y unas mayorías sociales cada vez más empobrecidas, abriendo una profunda herida en el bipartidismo, en donde el pacto social se habría roto en un principio más por arriba que por abajo. La ruptura desde abajo tampoco se hizo esperar y, con el surgimiento del 15M, ya en el año 2011, se pone en movimiento una cultura política nueva que en poco tiempo hace temblar los cimientos del Régimen 78 y de la Cultura de la Transición (Martínez, 2012; Delgado, 2014). La 
abdicación del Rey Juan Carlos I, el exitoso surgimiento de nuevos partidos como Podemos y los nuevos aires constituyentes demuestran el moribundo estado del Régimen del 78, y la llegada de nuevos replanteamientos entorno a su nacimiento, es decir, en torno a la Transición. Es en el momento en que el Régimen del 78 entra en una crisis profunda, cuando los expertos y la ciudadanía vuelven la mirada a su contexto de producción, que no es otro que el del proceso transicional. Esta lectura se da ahora con otros ojos, desde un presente desmitificador -por la propia realidad sangrante en la que se vive-, buscando las causas de muchos de los vicios del régimen justamente en su punto de partida. De este modo, se producen las segundas grietas (las primeras las producen los movimientos sociales por "la memoria histórica", como decíamos) dentro del relato mítico de la Transición. ¿ ¿ $\mathrm{Se}$ había hecho todo tan bien en la Transición -como siempre se había pensado- si teníamos una democracia low cost en donde resultaba tan fácil quitar derechos y aplicar recortes? ¿Qué había pasado realmente en esos años? ¿Es la Transición una victoria de la derecha franquista en vez de un proceso modélico de reconciliación? ${ }_{\mathrm{C}}$ Es la Transición un periodo conflictivo y oscuro, con más de mil muertos en las calles, y no un periodo de paz y consenso como nos han contado? De repente, la Transición se convierte en ese oscuro objeto de deseo, en donde todas las personas tienen algo que decir al respecto.

Todo ello, se da, además, en un contexto más amplio, de grandes cambios a nivel general y global. Por un lado está el inevitable relevo generacional, es decir la llegada a la palestra académica, política y mediática de una generación que no participó del proceso de cambio político de los setenta, que ha vivido enteramente en democracia y que no comparte ciertas pautas de la cultura política de la Transición y del Régimen del 78. Por otro lado se produce la entrada de la sociedad española en un mundo nuevo, producto del proceso de globalización (Beck, 1986), fuertemente vinculado a las nuevas tecnologías y a nuevos flujos de personas, mercancías e información (Castells, 2001). Esta verdadera revolución tecnológica ha configurado nuevas maneras de relacionarse que permiten nuevas formas de comunicación y de construcción identitaria, que a su vez dan lugar a una reconstrucción de la política desde espacios completamente distintos a los habituales en la sociedad industrial (como pudieron ser durante todo el siglo XX los medios de comunicación y la opinión pública, o los ámbito familiar y laboral, por citar los más importantes).

De este modo surgen nuevos actores, nuevas demandas, nuevas narrativas, y nuevos lugares de enunciación que resquebrajan hasta hacer estallar el relato homogéneo, cerrado y robusto de la Transición que hasta hace pocos años nadie ponía en duda. Es así como, de algún tiempo a esta parte, investigadores, artistas, periodistas, escritores o políticos -y, en realidad, gran parte de la ciudadanía- reconfiguran y reelaboran nuevos relatos sobre el periodo, como si de un puzzle se tratara, un puzzle que se hubiera vuelto a romper en sus piezas y ahora pudiésemos volver a intentar encajarlas de otras muchas maneras.

Y es que la Transición está de moda. La encontramos en la literatura (Cercas, 2009; Chirbes, 2011; Monedero, 2011), en las múltiples retrospectivas en el mundo del cine o del arte (Reina Sofía, 2012; Ateneo de Madrid 2013, Sala Berlanga 2014), en la televisión (Operación Palace, Cuéntame cómo pasó...) y en muchos de los discursos políticos 
(Rubalcaba, 2013, Rajoy, 2014; Monedero, 2013) sólo por citar los espacios más importantes. A veces se recupera para auparla aún más en un relato mítico, otras veces se utiliza como fuente de todos los males de la democracia. En otras ocasiones, se utiliza como habitat de relatos, culturas y biografías hasta hace poco no formuladas o investigadas, en un descubrimiento constante de nuevas realidades del proceso transicional, a veces conectadas con nuestro presente, otras no (Sánchez León, 2004; Labrador, 2009). En muchas ocasiones, se mira hacía ella con nostalgia, en otras, con reproche, en no pocas, con curiosidad. Pero en casi todas, con interés. El pasado reciente está siendo reelaborado.

Hay no obstante otros espacios en los que se está revisitando y reelaborando el relato de la Transición, espacios menos conocidos, estudiados o tenidos en cuenta. Espacios que se encuentran fuera de los ámbitos fundamentalmente hegemónicos, como la cultura, la escuela o los medios de comunicación (Gramsci, 1971), pero que son altamente interesantes para ahondar en los procesos de quiebre cultural y nuevas producciones narrativas hoy en día, ya que permiten dar cuenta de otras miradas, otras perspectivas, y otras dinámicas del proceso de reelaboración histórica que está teniendo lugar.

\section{La Querella Argentina contra los Crímenes del Franquismo: ipuede un proceso penal internacional reelaborar la historia colectiva?}

Es aquí donde adquiere interés la Querella Argentina contra los Crímenes del Franquismo. Esta querella, presentada por familiares de asesinados y desaparecidos durante la dictadura franquista y por diversas asociaciones argentinas y españolas el 14 de abril de 2010 en Buenos Aires, surge desde la frustración de muchos de los colectivos de memoria en España, al encontrar trabas judiciales de todo tipo en el intento de procesamiento del régimen franquista en nuestro país que se dio desde 2008 al 2012 (Chinchón, 2012). En este sentido, tras las limitaciones ya mencionadas de la ley de Memoria Histórica del PSOE, ya desde 2007 se busca, desde los movimientos sociales memorísticos y las asociaciones de víctimas, la aplicación de los mecanismos de verdad, justicia y reparación, a través de la jurisdicción española. En este contexto, el juez Baltasar Garzón instruyó la famosa Causa contra los Crímenes del Franquismo (2008-2012), por la que será acusado de prevaricación por Falange Española, y, en consecuencia, apartado de su cargo por el Consejo General del Poder Judicial. Si bien en el Auto del 27 de Febrero de 2012 el Tribunal Supremo absolvió de esa acusación al juez Garzón, cerró de manera temporal la posibilidad de juzgar los crímenes del Franquismo en España.

En este contexto, muchas de las asociaciones que habían interpuesto querellas y denuncias en España, cruzaron el charco para probar suerte en Argentina. La elección de este país, y no otro u otros tribunales supra-estatales, estaba motivada por varias razones. En primer lugar, por la relación del propio país argentino con España, vinculados estrechamente por una historia común y los diversos flujos migratorios que la acompañan, siendo fundamental el exilio político de la ciudadanía de uno y otro país en sus respectivas fechas de dictadura y represión (en España, de 1939 a 1977; en Argentina, de 1976 a 1983). En segundo lugar, por las actuaciones de tribunales de países extranjeros amparados en las nuevas leyes de Justicia Universal, que se dieron a lo largo de la última década del 
siglo XX y la primera del Siglo XXI, en relación al procesamiento de diferentes dictaduras del Cono Sur (entre ellas, Argentina desde, paradójicamente, la justicia española). Se entendía, en un relato de viaje de ida y vuelta, que Argentina podría hacer por las víctimas del franquismo lo que España había hecho por las víctimas de la dictadura cívico-militar argentina (Baby, 2011).

Durante estos primeros cuatro años (2010-2014) la Querella Argentina se ha ido transformando en una causa penal internacional de gran envergadura. Se documentan en la actualidad más de trescientos querellantes y muchos más denunciantes de varios países, que cuentan con una gran coordinadora internacional de apoyo (la Coordinadora Estatal de Apoyo a la Querella Argentina o CEAQUA), la cual engloba varias plataformas internacionales y otras cuantas sub-estatales, a su vez formadas por asociaciones de memoria histórica y derechos humanos, y colectivos de víctimas del franquismo de todo tipo: ex-presos políticos torturados, familiares de personas desaparecidas, de niños robados, o de trabajadores-esclavos, víctimas del exilio o preventorios, y un largo etcétera. Todos estos colectivos, al movilizarse, argumentar y sumar esfuerzos, ponen en circulación nuevos relatos y narrativas sobre la Guerra Civil, la dictadura franquista y la Transición, produciendo verdaderas narraciones de resistencia (Martínez, 2013) que chocan contra el relato mítico de la Transición.

Mi argumento es que es una labor necesaria adentrarse en el estudio de este tipo de espacios sociales, tradicionalmente no definidos como productos culturales, pero que, como cualquier otro, revisitan y reformulan, desde la perspectiva actual, el relato mítico de la Transición. La querella argentina contra los crímenes del franquismo, y el espacio social que genera, es un producto cultural diferente, por sus propias dinámicas y su propio campo de juego, que hace que sea necesario seguir su proceso con una mirada atenta que promete enriquecer el debate despertado en los otros campos culturales ya mencionados.

Por otro lado, -y esto es fundamental- una de las dimensiones más interesantes de estas narraciones de resistencia es que despliegan unos discursos de gran eficacia simbólica, como es el caso de los discursos de Derechos Humanos, hasta el punto de que es posible argumentar que un proceso penal internacional puede ofrecer el potencial simbólico para reelaborar de manera eficaz la historia colectiva de España. Eficacia simbólica quiere decir aquí la capacidad de ciertos discursos, por tratarse de discursos producidos en lugares de enunciación de expertos, de prestigio o de autoridad, de encontrar gran complicidad en los agentes que reciben como válido o verdadero ese discurso (Bourdieu, 2008).

En el caso de los discursos que beben del marco jurídico de los Derechos Humanos, nos encontramos con una fuerte eficacia social debida, en primer lugar, a su legalidad y legitimidad a nivel internacional, y a la manera en que su contenido constituye en sí mismo un envite para la movilización o desmovilización de los agentes sociales (Devillard y Baer, 2010). En segundo lugar, el marco jurídico de los Derechos Humanos invoca un campo político determinado, como es el de la "comunidad internacional", y un campo simbólico, como es el de "Justicia Universal" que está cobrando cada vez más fuerza en el ámbito internacional, con procesos como la condena de los regímenes de Chile, Argentina, u otros países sudamericanos, como ya hemos subrayado (Baby, 2011; Barros, 2013). Ello otorga a esa comunidad internacional un papel de "arbitraje" eficaz e interesante en las cuestiones 
que nos conciernen, así como una capacidad de "oficialización" e "institucionalización" sólo equiparables a un poder legislativo o ejecutivo. Este desplazamiento de la comunidad nacional (España) a la comunidad internacional y al lenguaje de Derechos Humanos permite además un nuevo lugar de reconocimiento para los colectivos de memoria histórica, ya que, si bien la crisis económica ha relegado en un segundo plano los debates sobre la memoria histórica, la gestión de esta misma crisis por parte de los partidos políticos a través de recortes fundamentales de derechos civiles, políticos y sociales permite una posible rearticulación de la lucha "por la memoria histórica" en esa lucha "por los derechos humanos" de la querella, pudiendo derivar en una pugna política que pueda obtener una mejor recepción e identificación en la ciudadanía española en este contexto actual de recorte de derechos y polítización general de los mismos.

En tercer lugar, las denuncias en pos de la Justicia Universal y los Derechos Humanos tienen una gran capacidad de objetivar sus quejas y des-singularizar la relación entre los actantes (Boltanski, 1990), ya que transforman con facilidad los conflictos personales (una tortura, un robo) en conflicto categoriales (represión política), arma poderosa a la hora de tener posibilidad de éxito del llamado a la opinión pública. Por último, las acciones colectivas que "reproducen interpretaciones del pasado, (...) al mismo tiempo contribuyen a transformar las condiciones que harán (o no) posibles nuevos campos de sentido, que le otorgan a la memoria su poder de construir versiones contrahegemónicas" (Piper e Iguiñez, 2013). Las víctimas del franquismo podrían acabar teniendo, entonces, la llave de la reelaboración de nuestra historia.

Es importante, por otro lado, matizar esta posible eficacia o efectividad social del discurso de los Derechos Humanos en el contexto español de la Querella Argentina. En primer lugar, en España encontramos una débil cultura de los derechos humanos, en donde muchos colectivos como Amnistía Internacional (2008) o la Asociación Pro Derechos Humanos de España (2007) llevan años denunciando o visibilizando la falta de educación y cultura en Derechos Humanos que encontramos tanto en el poder legislativo -todavía faltan por aplicar o incluir leyes de Derecho Penal Internacional en el marco jurídico española-, como en la administración pública -encontramos una ausencia sintomática de temarios de formación en Derechos Humanos en los cuerpos de seguridad del Estado, en la judicatura española, en los planes de estudio de educación secundaria y universitaria-. Todo ello conlleva posibles dificultades a la hora de recibir como legítimo el discurso de la Querella Argentina. En segundo lugar, hay que constatar que la herida social que dejó la dictadura franquista es diferente respecto a los casos de los países del Cono Sur en una cosa fundamental, como es la variable temporal, ya que el tiempo transcurrido -mucho más largo en el caso español- de muchos de los crímenes cometidos por el franquismo puede difuminar y debilitar esta huella de nuestro pasado.

\section{El discurso mítico de la Transición $V s$ el discurso de los Derechos Humanos}

En la Querella Argentina y en el espacio simbólico que genera se puede observar una pugna clara por la historia legítima de la España del siglo XX. En este ring de boxeo histórico, encontramos dos discursos fuertemente enfrentados, los dos con una alta eficacia 
social y la posibilidad de ser entendidos como discursos de verdad: el discurso mítico de la Transición, y el discurso de Derechos Humanos. En interesante subrayar que los dos discursos parten de entender la Transición como barrera: una como muro de contención, y otra como muro a derribar. En las próximas páginas planteo un análisis más profundo de cada uno de esos relatos.

En relación al primer discurso, el discurso hegemónico de la Transición, apuntado brevemente en el inicio del artículo en sus principales características, lo que aquí interesa ahora son las propiedades particulares que adquiere este discurso en el marco jurídico y político de la querella. En primer lugar, una de sus claves fundamentales es el peso legal, político y simbólico que otorga este relato a la Ley de Amnistía, promulgada el 15 de Octubre de 1977. Para los agentes sociales que ponen en práctica el discurso mítico de la Transición en el espacio social de la querella -los partidos políticos, los jueces españoles, y los medios de comunicación- la Ley de Amnistía es definida como la voluntad popular de una sociedad libre (el dictador Francisco Franco murió en 1975), en un ejercicio cristiano de perdón, reconciliación y mirada hacia el futuro. Así por ejemplo la embajadora española ante la Organización de las Naciones Unidas, Ana Menéndez, contestó con estas palabras al relator de la Comisión de Derechos Humanos Pablo de Greiff, en una reunión reciente en Ginebra:

\begin{abstract}
No estamos ante una ley de punto final otorgada por la dictadura perdonándose a sí misma, sino una ley adoptada por los partidos parlamentarios democráticamente elegidos y plenamente conscientes de la importancia del paso que están dando. (...) Solo a través del olvido y el perdón era posible la reconciliación (Menéndez, 2014).
\end{abstract}

Esta versión sobre la Ley de Amnistía siempre conlleva la lectura implícita de la Guerra Civil como consecuencia trágica de esa polarización política desmesurada e ingobernable durante la Segunda República, en la que tanto unos como otros tuvieron parte de la culpa.

En segundo lugar, en este discurso hegemónico de la Transición aplicado a la Querella todo lo que sea hablar de la Guerra Civil y la Dictadura es abrir viejas heridas, volver a un discurso "guerracivilista", desenterrar un pasado que sólo puede volver a provocar crispación y conflicto. Es decir, que la crítica a la Transición lleva directa e inevitablemente a otro contexto de conflicto e inestabilidad. En palabras del portavoz del PP en la Comisión Constitucional: "Tenemos que salir de la dinámica de guerra. No cuenten con nosotros para dividir a esa sociedad (...) y para poner en riesgo lo mejor que hemos hecho como sociedad, que es la Transición" (La Vanguardia, 25 de Mayo 2013). Por último, ante el aumento de las presiones internacionales sobre España para iniciar mecanismos profundos de verdad, justicia y reparación (Informes de Amnistía Internacional 2012, 2013; Comisión de Derechos Humanos de Naciones Unidas 2002, 2014) el gobierno español ha operado con otro reajuste interesante, como es el cambio de un régimen de Transición modélico a un régimen de Transición "único" o singular (Delgado, 2014). En palabras de la embajadora de España ante la ONU: "La Transición española es también un caso especial, porque constituye un caso de reconciliación nacional sin justicia penal" (Menéndez, 2014, la cursiva es mía). En otras palabras, sin bien el 
modelo transicional español no comparte la mayoría de las bases de los tratados ratificados por España de Justicia Transicional y Derechos Humanos (Chinchón, 2012), funcionó para los españoles y las españolas, por lo que no necesita un tratamiento posterior.

En relación al discurso de los Derechos Humanos, éste es el discurso más usado o puesto en práctica por la mayoría de agentes sociales en el espacio social de la querella, lo cual tiene mucho sentido al estar en un espacio de carácter jurídico-trasnacional. Los agentes que despliegan mayoritariamente este discurso son las asociaciones de víctimas, los abogados querellantes, los organismos internacionales (ONU, Amnistía Internacional..), la judicatura argentina y los técnicos del proceso penal (forenses, juristas, peritos, científicos sociales, y un largo etcétera). Según Ferrándiz (2014) en España se está produciendo un incremento en el empleo del lenguaje de los Derechos Humanos, lo cual produce una retraducción y una reapropiación de éste por parte de los sujetos, y una puesta en práctica en contextos locales que cambian o modifican parte de su mensaje.

La lectura de la Ley de Amnistía, por ejemplo, aparece abiertamente enfrentada a la lectura que de ella se hace en el discurso mítico de la Transición. En el marco de los Derechos Humanos, la ley de Amnistía es definida como una ley de punto final que principalmente cerró la posibilidad de juzgar a aquellos sujetos que cometieron crímenes de Lesa Humanidad (crímenes imprescriptibles) durante la dictadura y la represión franquista, más allá de amnistiar los presos políticos de la lucha antifranquista. En este sentido, es significativo el número de presos que salieron de las cárceles franquistas con la ley de Amnistía de 1977: de las decenas de centenares de presos políticos a la muerte del dictador, sólo 89 salieron con esta ley (El País, 15 octubre 1977), ya que la gran mayoría habían salido con los indultos y las amnistías anteriores. Así lo explica un portavoz de la Coordinadora Estatal de apoyo a la Querella Argentina (CEAQUA) y ex-preso político, en una rueda de prensa de su plataforma con motivo de la visita a España de la jueza argentina que lleva el proceso: "En este país se construyó la democracia mirando para otro lado. Así de sencillo. La clave de bóveda de la Transición es la elaboración de una ley de amnistía cuando ya los presos políticos del franquismo estábamos en la calle y es una ley de amnistía fundamentalmente dirigida hacia los represores franquistas"1. Además, desde el discurso de estos agentes sociales, la Ley de Amnistía no se enmarca en un contexto de libertad y voluntad popular, pero sí en uno de miedo, inestabilidad e incertidumbre: "En el 82 había mucha gente aterrorizada por lo que podía pasar, y el ruido de sables era utilizado sistemáticamente como una forma de presión política..." (Chato, Portavoz de CEAQUA, rueda de prensa con motivo de la visita de la jueza argentina a España, 28 de mayo 2014). La ley de Amnistía deja de ser una decisión consciente, deliberada y libre del pueblo español, para convertirse en una estrategia de autoprotección del régimen franquista.

Por otro lado, esta lectura de la ley de Amnistía también contiene un relato sobre los hechos anteriores a la Transición, un relato completamente diferente del empleado por los agentes sociales que ponen en práctica el discurso mítico de la misma. En este sentido, la guerra ya no es una tragedia causada por el conflicto y la desmesura política de la Segunda

\footnotetext{
${ }^{1}$ Estas declaraciones de los portavoces de CEAQUA, y las que se reproducen en las siguientes páginas, están recogidas en el trabajo de campo enmarcado en el proyecto de tesis doctoral de la autora, todavía no publicado hasta la fecha.
} 
República, sino la consecuencia de un golpe de Estado cívico-militar a un Estado democrático y de derecho que, al no triunfar en sus primeros días, se convierte en una contienda militar de tres años de duración. En esta lectura de la Guerra Civil, la victoria de estos últimos y la instauración de una dictadura desembocó en un enorme acto sistematizado de represión, violencia y muerte, un acto que conlleva graves violaciones de Derechos Humanos (Auto del Juez Garzón, 16 de Noviembre 2008; Amnistía Internacional, 2012; De Greiff, 2014). En palabras de una hija de exiliados políticos de la Guerra Civil encontramos este mensaje de una manera clara y concisa: "He oído a dos ministros españoles decir el año pasado, el señor Margallo y el señor Gallardón, en vez de hablar de los deportados españoles, decían: disidentes españoles. Ellos fueron disidentes, sus familiares, ellos fueron los que asaltaron un gobierno democráticamente elegido". (Elsa, portavoz de CEAQUA, Ronda de la dignidad en la Plaza del Sol, mayo 2014).

En tercer lugar, en contra de los gritos al cielo y de las acusaciones de "guerracivilismo" y de crispación que algunos agentes sociales despliegan desde el discurso mítico de la Transición, las personas que denuncian la represión franquista como Crímenes de Lesa Humanidad consideran que no se dará un verdadero cierre del proceso histórico hasta que se sepa toda la verdad sobre los hechos, se enjuicie a los culpables y se repare a las víctimas. De este modo, exigir el cumplimiento de las recomendaciones de la Comunidad Internacional no es volver a abrir heridas, ya que -en un ejemplo metafóricohasta que "las fosas de los desaparecidos permanezcan cerradas, las heridas siempre permanecerán abiertas" (Declaración de un familiar de un desaparecido a las puertas de la Audiencia Nacional, 29 de mayo 2014). En palabras del relator ante la comisión de Derechos Humanos de la ONU, Pablo de Greiff, esto se traduce, en el lenguaje jurídico de la Justicia Universal, en la imprescriptibilidad de esos crímenes. Lo vemos respecto al caso de la desaparición forzada:

Además de los estándares internacionales que establecen la imprescriptibilidad de los delitos de lesa humanidad, el derecho internacional establece que, en relación con los casos de desaparición forzada, los plazos de prescripción deben contar a partir del momento en que cesa la desaparición forzada, es decir, desde que la persona aparece con vida o se encuentran sus restos. El Relator Especial nota con preocupación que durante la visita, de forma consistente, las autoridades (españolas) negaron el carácter continuado de la desaparición forzada, presentando este principio como un sinsentido jurídico (De Greiff, 2014)

Por último, en contra de la imagen de la España, primero modélica, y luego "única" que manejan los agentes sociales que ponen en circulación el discurso hegemónico de la Transición, los agentes sociales que se enmarcan en el discurso de Derechos Humanos, presentan la imagen de una "España deudora", atrasada en el ejercicio de reparar a las víctimas de las violaciones de Derechos Humanos cometidas en su territorio y en el ejercicio de garantizar el conocimiento de la verdad a toda la ciudadanía: "Partimos de la base de que se cometieron en España uno de los mayores genocidios que se cometieron en el Siglo XX, ignorado, tapado, hurtado a las nuevas generaciones"(Carlos Slepoy, abogado de la CEAQUA, rueda de prensa, 30 de Mayo 2014). Esta imagen del gobierno español 
como moroso con las demandas de las víctimas de la Guerra Civil y la Dictadura no es una novedad, siendo un discurso desplegado, por ejemplo, en las demandas de los llamados "Niños de la URSS" (Devillard et al, 2001).

\title{
Las (nuevas) víctimas del franquismo, ${ }_{\mathrm{d}}$ las (otras) víctimas de la Transición?
}

\author{
Naturalmente que la Transición tuvo cosas \\ positivas, pero tiene un pecado de origen tan \\ terrible, tan tremendo, que ha dejado a la mitad \\ de esta sociedad absolutamente desamparada.
}

CARLOS SLEPOY, abogado de la CEAQUA, 2014.

Respecto a los discursos sociales y los sujetos que los ponen en circulación, es necesario matizar que estos discursos no se encuentran en la sociedad en "estado puro", expuestos y formulados como acabamos de presentarlos. Todo lo contrario, estos relatos y narrativas son puestos en práctica, como ya hemos señalado, por determinados agentes sociales en contextos situados. La mayoría de la literatura académica sobre la historia reciente de nuestro país ha centrado su análisis, por un lado, en un abordaje ligado a mecanismos macro, generales o abstractos, siendo limitada para recoger la riqueza subjetiva de los actores que han formado parte de esa historia (Devillard et al, 1995); por otro lado, se han recogido testimonios, memoria y recuerdos sin analizar en profundidad el contexto de producción de todos esos discursos y sin reconstruir la génesis social de los mismos (Bourdieu, Passeron y Chamboredon, 1998). Es importante señalar, por el contrario, que los agentes sociales no aplican ni "mecánicamente" ni "maquiavélicamente" los discursos, sino que los ponen en circulación en función de sus estrategias, su cultura política de origen, su contexto presente, sus posiciones cambiantes o sus intereses particulares, conscientes o inconscientes, que pueden ser de todo tipo. A modo de conclusión de este artículo, voy a reflexionar sobre la relación entre discursos, sujetos y realidad dentro de los sujetos querellantes, y de la constitución de un nuevo colectivo en torno a ella, como es el de "Víctimas del Franquismo".

La gran mayoría de las personas que se han querellado en la causa penal internacional de Buenos Aires llevan encima de sus hombros, como enormes menhires invisibles, otras narrativas sobre las historia de nuestro país. Son relatos incorporados o encarnados, reformulados en historias de vida, de lucha, de traumas o silencios y hasta, en algunos casos, en enfermedades, en un claro proceso de somatización de la otra historia, que no ha podido salir de esos espacios de síntoma o marginalidad hasta hace una década. Pueden ser víctimas directas de la represión, como encarcelados, torturados, familiares de desaparecidos y niños robados, trabajadores-esclavos y un largo etcétera. $\mathrm{O}$ pueden ser víctimas indirectas de ella, como muchos nietos con una historia familiar basada en el silencio y en el trauma, personas que todavía hoy en día arrastran un estigma de "rojos" en su localidad, o muchas familias todavía con miedo. En algunos casos son verdaderas "narraciones de resistencia" como apuntaba Martínez (2013), en un claro posicionamiento de lucha y de resistencia, en donde suele haber un claro marco político detrás, acompañándoles. En otros, sin embargo, se asemejan en mayor medida a lo que he 
denominado como "narraciones afectadas", donde los susurros, los miedos y los traumas han reinado en gran parte de estas historias de vida.

Lo que se encuentra en todas estas personas es la inclusión en sus discursos y en sus prácticas tanto de esta otra historia de España como también la historia dominante de nuestro país, y en particular el relato mítico de la Transición. Y es que, los relatos nunca se encuentran aislados unos de otros en la realidad y en la vida social de las personas, sino que se entrelazan y atraviesan de mil maneras a los sujetos sociales, desembocando en procesos de subjetivación densos y ambivalentes. De este modo, las víctimas del Franquismo han sido, en un primer momento, víctimas del propio sistema dictatorial y de las propias prácticas represoras: la represión física y simbólica, la muerte, la cárcel, el exilio, la tortura, la pobreza, la exclusión, o el trauma son algunas de ellas. En un segundo momento, sin embargo, llegaron a ser muchas de ellas (no todas) de nuevo víctimas y/o cómplices, esta vez del proceso transicional y del sentido común impuesto o construido por el mismo (tanto desde las élites, como desde la misma ciudadanía). Todo ello conllevó en cierta medida a la desarticulación (impuesta o no) de importantes ejercicios de memoria, como exhumaciones, homenajes o búsquedas, que se estaban dando en un número importante y todavía desconocido en la actualidad. Algunos trabajos contemporáneos de historiadores y expertos están abriendo todo este campo de investigación, como es el caso de la historiadora Zoe de Keranga, que investiga las exhumaciones durante la Transición y que confirma un número elevado de las mismas, centenares, en una dinámica de memoria privada y familiar que, sin embargo, parece paralizarse a raíz del Golpe de Estado de 1981 y de la amenaza involucionista. Como ya sabemos, "no era el momento".

Sin embargo, por el relato mítico de la Transición, tampoco lo fue más adelante. Y no fue así porque el sentido común que se instauró en la democracia, ese marco de interpretación hegemónica que mencionábamos al principio del artículo, no permitía un lugar para las víctimas del franquismo, al estar ya "cerrado" ese capítulo para la sociedad española. Así, en un ejercicio de auto-censura típico de los procesos de hegemonía, muchas de las personas que habían sido represaliadas, volvieron a hablar de todo ello (si se hablaba) en casa, entre susurros, con miedo y con vergüenza. Este sentido común les ha afectado considerablemente y puede explicar -en parte- el opresivo y largo silencio de muchas de estas personas respecto a muchas de estas cuestiones.

Se abre la posibilidad de que el marco de Derechos Humanos y la eficacia simbólica que éste despliega, pueda generar un proceso de reelaboración de la historia de España por parte de estos sujetos sociales, inaudito hasta la fecha. Este proceso de reelaboración puede comenzar con un uso estratégico (consciente o inconsciente) de este marco de interpretación por parte de las asociaciones de víctimas, importado desde el éxito de otros movimientos de víctimas como en Argentina, Chile o Sudáfrica. En un segundo momento, esta "utilización" podría, en algunas ocasiones, acabar desarrollando en ellos verdaderos procesos de subjetivación que repercutan en el propio proceso identitario y (auto)biográfico de la persona. Todo ello, a su vez, puede generar dinámicas de empoderamiento y legitimación que les permita, por fin, definirse como interlocutores válidos del proceso de reelaboración de las narrativas sobre nuestro país y nuestra historia. 


\section{Conclusión}

Como se espera haber argumentado con rigurosidad a lo largo de todo el texto, el contexto actual de crisis, quiebre y posibles replanteamientos del relato mítico de la Transición es ya una realidad empírica, la cual conlleva, entre todas muchas cosas, una relectura de las narrativas sobre la historia del siglo XX español. En este presente incierto de nuevas miradas, nuevos actores y nuevas lugares de enunciación, considero profundamente interesante y pertinente el estudio de caso de la "Querella Argentina" como un espacio social con potencial para acelerar la descomposición del relato mítico e intervenir en este nuevo contexto de reelaboración colectiva. Por un lado, este espacio despliega un discurso ético-político, el discurso de Derechos Humanos, que podría hacer frente de una manera eficaz al relato reconciliador de la transición en la pugna política y discursiva en la que se encuentran. Por otro lado, este discurso y el propio proceso judicial permite por primera vez en la historia española unos soportes (auto)biográficos a las víctimas del franquismo, que podrían derivar en procesos de subjetivación y empoderamiento como sujetos legítimos en el nuevo marco de interpretación histórica. Todo ello podría, finalmente, desencadenar un proceso de democratización de la memoria histórica nunca visto en la España contemporánea, dándole la vuelta a la famosa frase de Winston Churchill, y reescribir, por fin, la historia desde el lugar de los vencidos. 


\section{Bibliografía Citada}

Abc.es. "El gobierno apela a la Transición frente a los independentistas". Abc.es $(18 / 09 / 2014)$.

Aguilar, Paloma. "Los debates sobre la memoria histórica". Claves de Razón Práctica 19 (2007): 64-69.

Aguilar, Paloma (2008). Políticas de la memoria y memorias de la política. Madrid: Alianza Editorial.

Aguilar, Paloma. "Jueces, represión y justicia transicional en España, Chile y Argentina". Revista Internacional de Sociología 71 (2) (2013): 281-308. DOI: 10.3989/ris.2011.11.14

Arostegui, Julio (1996). La guerra civil, 1936-1939: la ruptura democrática. España: Temas de Hoy.

Asociación Por los Derechos Humanos España (APDHE). (2007) Treinta años de Derechos Humanos En España. España: Icaria Editorial.

Baby, Sophie. "Latinoamérica, ¿un desvío necesario? Baltasar Garzón, de Pinochet a Franco". Revista Amnis. Memorias de la Guerra Civil española: transmisión, reapropiación y uso, Europa-América Latina Congreso internacional (2009): IHEAL, París.

Barros, Carlos. "Historia, memoria y Franquismo". Historia Actual Online 3 (2014): 153171.

Beck, Ulrich (1998): La sociedad del riesgo: hacia una nueva modernidad. Madrid: Paidós Ibérica.

Bernecker y Sören (2009). Memorias divididas. Guerra Civil y franquismo en la sociedad y la política españolas (1936-2008), Madrid: Editorial Abada.

Boltansky, Luc (1990). El amor y la justicia como competencias. Paris: Metailé.

Bonet, Jordi y Alija, Rosa Ana. "Impunidad, Derechos Humanos y Justicia Transicional". Cuadernos de Deusto de Derechos Humanos 1 (2009).

Bourdieu, Pierre (2008). Qué significa hablar. Madrid: Editorial Akal.

Bourdieu, Pierre; Passeron, Jean-Claude y Jean-Claude Chamboredon (1998). El oficio del Sociólogo. Madrid: Siglo XXI.

Casanova, Julián (2008). República y Guerra Civil. Ediciones de Historia Crítica. España: Siglo XXI.

Castells, Manuel (2001). La Era de la Información. Vol. II: El poder de la identidad. México, Distrito Federal: Siglo XXI Editores.

Cercas, Javier (2001). Soldados de Salamina. Barcelona: Tusquets editors.

Cercas Javier (2009). Anatomía de un instante. España: Literatura Random House.

Chacón, Dulce (2002). La voz dormida. Alfaguara. 
Chinchón Alvarez, Javier "El tratamiento judicial de los crímenes de la Guerra Civil y el Franquismo en España. Una visión de conjunto desde el Derechos Internacional" Cuadernos de Deusto de Derechos humanos 67 (2012).

Chirbes, Rafael (2011). La caída de Madrid. Madrid: Editorial Anagrama.

De Greiff, Pablo (2014). "Informe del Relator Especial sobre la promoción de la verdad, la justicia, la reparación y las garantías de no repetición. Misión a España". Ceaque.org.

Delgado, Luisa Elena (2014). La nación singular. Fantasías de la normalidad democrática española (1996-2011). España: Siglo XXI.

Devillard, Marie Jose; Pazos, Alvaro; Castillo, Susana; Medina, Nuria y Touriño, Eva "Biografías, subjetividad y ciencia social. Crítica del enfoque biográfico desde una investigación empírica". En Revista Política y Sociedad 20 (1995): 143-156.

Devillard, Marie Jose; Pazos, Alvaro; Castillo, Susana y Medina, Nuria (2001). Los niños españoles en la URSS. Narración y memoria. Barcelona, Editorial Ariel.

Devillard Marie Jose, y Baer, Alejandro. "Antropología y derechos humanos: multiculturalismo, retos y resignificaciones". Revista de Antropología Social 20, (2010): 25-52.

Eldiario.es "Rubalcaba: Soy un caso prototípico de la Transición". Eldiario.es $(11 / 01 / 2013)$.

El País. "Las Cortes aprobaron la Amnstía”. El País (15/10/1977).

Escolar, Ignacio. (coord.). "El fin de la España de la Transición". Cuadernos de Eldiario.es 1 (2013): 3 .

Etxeberria, Francisco. "Restos humanos del Frente del Jarama en la Guerra Civil 19261939". Munibe Antropología-Arkeología, 60, (2009): 281:288.

Évole, Jordi (2014). Operación Palace (T.V.) España: SVII Films / Atresmedia Televisión.

Ferrándiz, Franciso. "De las fosas comunes a los derechos humanos: el descubrimiento de las "desapariciones forzadas" en la España contemporánea. Revista de Antropología Social 19 (2010): 161-189.

Ferrándiz, Francisco (2014). El Pasado bajo tierra. Exhumaciones contemporáneas de la Guerra Civil. España: Anthropos.

Gallego, Ferrán (2008). El mito de la Transición: la crisis del franquismo y los orígenes de la democracia (1973-1977). España: Crítica.

García-Alix, Carlos (2004) El honor de las injurias, España. No hay penas.

Garzón, Baltasar. (2010). Garzón contra el franquismo. Los autos íntegros del juez sobre los crímenes de la dictadura. Madrid: Diario Público.

Gramsci, A. (1971): Scritti Politici, Roma: Editori Riunitu.

Grandes, Almudena (2007). El corazón helado. Barcelona: Tusquets editors.

Halbwachs, Michele (2004). La memoria colectiva. Zaragoza: Prensa Universitaria.

Internacional, Amnistía (2008). "30 Años haciéndonos escuchar”.

Internacional, Amnistía (2012). "Casos Cerrados, heridas abiertas".

Internacional, Amnistía (2013). "El tiempo pasa, la impunidad permanece". 
Juliá, Santos. "Echar al olvido: Memoria y amnistúa en la Transición", Claves de Razón práctica 129 (2003): 14-25.

Juliá, Santos (2004). Historia de las dos Españas. España: Ediciones Taurus.

Ley 52/2007, de 26 de diciembre "Por la que se reconocen y amplían derechos y se establecen medidas a favor de quienes padecieron persecución o violencia durante la guerra civil y la dictadura".

Labrador, Germán (2009). Letras Arrebatadas. Poesía y Química en la Transición Española. España: Editorial Devenir.

La Vanguardia. "El PP y UPD evitan condenar el franquismo". La Vanguardia. (21/05/2013).

Madrid, Ateneo (2013). "Mujeres bajo sospecha. Memoria y Sexualidad 1930-1980”. Del 11 de enero al 11 de febrero de 2013. Inauguración 10 de enero. Exposición comisariada por Raquel Osborne y María Rosón.

Martínez, Guillem (2012). CT o La Cultura de la Transición. Barcelona: Editorial DeBolsillo.

Martínez, Mario "La comuna de los presos, o de la memoria del antifranquismo como huella, deber y deseo", Revista Viento Sur, 126(2013): 51-59.

Menéndez, Ana (2014). "Intervención de la embajadora española ante las Naciones Unidas". ceaqua.org.

Moa, Pio (2003). Los mitos de la Guerra Givil. Madrid: La Esfera de Los Libros.

Monedero, Juan Carlos (2011). La Transición contada a nuestros padres. Madrid: Editoral Catarata.

Monedero, Juan Carlos (2013). "Salvar a la Transición para seguir en política". www.comiendotierra.es.

Montoto, Marina (2012). "Los discursos de la Transición Española: del discurso hegemónico a las visibilización de otros relatos". Trabajo final de máster, inédito.

Montoto, Marina y Vázquez, Ángela. "El muerto no estaba tan sano. La desafección respecto al sistema político español actual. Algunas aportaciones" Congreso Sociología Federación Española de Sociología (2013): Comunicación oral.

Naldini, Manuela (2006). Le politche sociali in Europa. Transformazioni dei bisogni e rispota di Policy. Roma: Carocci.

Norra, Pierre (1984). "Entre Memoria e Historia". Les Lieux de Mémoire, 1: La République París, Gallimard, 1984, pp.XVII-XLIL. Traducción para uso exclusivo de la cátedra Seminario de Historia Argentina Prof.Femando Jumar C.U.R.Z.A. Univ. Nacional del Comahue.

Oñate, Pablo (1998). Consenso e ideología en la Transición española. Centro de Estudios Político y Constitucionales.

Pérez Díaz, Víctor (1993). La primacía de la sociedad civil: el proceso de formación de la España democrática. Madrid: Alianza Editorial.

Piper, Susan y Iguiñez, Lupicinio. "Psicología Social de la memoria: Espacios y Políticas del recuerdo". Revista PSYKHE 22, 2(2013): 19-31. DOI: 10.7764/psykhe.22.2.574 
Reina Sofía, Centro de Arte Contemporáneo (2012). "La Escritura Desbordada, poesía experimental española latinoamericana, 1962, 1982".

Rosa, Isaac (2007). ;Otra maldita novela sobre la Guerra Civil!. Barcelona, Seix Barral.

Sánchez Léon, Pablo e Izquierdo Martín, Jesús (2006). La guerra que nos han contado: 1936 y nosotros. Madrid: Alianza editorial.

Sánchez León, Pablo "Estigma y memoria de los jóvenes en la Transición", en La memoria de los olvidados. Un debate sobre el silencio de la represión franquista" (2004): Ámbito ediciones.

Sánchez León, Pablo "Overcoming the violent past in Spain: 1939-2009". European Review 20, 4 (2012): 492-504. DOI: 10.1017/S1062798712000063

Teitel, Ruge G. "Transitional Justice Genealogy". Harvard Human Rigths 16 (2003): 6994.

Todorov, Tzvetan (2000). Los abusos de la memoria. Barcelona: Paidos.

\section{Filmografia y audiovisuales:}

Armengou, Montse (2001). El convoy de los 927. España: Televisió de Catalunya.

Bernadeu, Miguel Angel (2001-actualidad). Cuéntame cómo pasó. España: RTVE- Grupo Ganga.

Cuerda, Jose Luis (1999). La Lengua de las mariposas. España: Sogetel.

Del Toro, Guillermo (2006). El laberinto del Fauno. España- Mexico-USA: Estudios Picasso Fábrica de Ficción / Tequila Gang / Tele5 / Sententia Entertainment.

Española, Radio Televisión (1995-Actualidad) Cine de Barrio. RTVE.

Sala Berlanga. "40 años no es nada. Reflejos y derivas del cine militante español contemporáneo". Ciclo de cine, 6 al 16 de septiembre de 2014.

Uribe, Imanol. (2002) El viaje de Carol. España-Portugal: Sogecine / Aiete / Ariane Films España / Take 2000 Portugal. 